Wright State University

CORE Scholar

4-1-2005

\title{
Study of the Photoluminescence of Phosphorus-Doped p-Type ZnO Thin Films Grown by Radio-Frequency Magnetron Sputtering
}

\author{
Dae-Kue Hwang \\ Hyun-Sik Kim \\ Jae-Hong Lim \\ Jin-Yong Y. Oh \\ Jin-Ho Yang
}

See next page for additional authors

Follow this and additional works at: https://corescholar.libraries.wright.edu/physics

Part of the Physics Commons

\section{Repository Citation}

Hwang, D., Kim, H., Lim, J., Oh, J. Y., Yang, J., Park, S., Kim, K., Look, D. C., \& Park, Y. S. (2005). Study of the Photoluminescence of Phosphorus-Doped p-Type ZnO Thin Films Grown by Radio-Frequency Magnetron Sputtering. Applied Physics Letters, 86 (15), 151917.

https://corescholar.libraries.wright.edu/physics/91

This Article is brought to you for free and open access by the Physics at CORE Scholar. It has been accepted for inclusion in Physics Faculty Publications by an authorized administrator of CORE Scholar. For more information, please contact library-corescholar@wright.edu. 


\section{Authors}

Dae-Kue Hwang, Hyun-Sik Kim, Jae-Hong Lim, Jin-Yong Y. Oh, Jin-Ho Yang, Seong-Ju Park, Kyong-Kook Kim, David C. Look, and Y. S. Park 


\title{
Study of the photoluminescence of phosphorus-doped $p$-type ZnO thin films grown by radio-frequency magnetron sputtering
}

\author{
Dae-Kue Hwang, Hyun-Sik Kim, Jae-Hong Lim, Jin-Yong Oh, \\ Jin-Ho Yang, and Seong-Ju Park ${ }^{\text {a) }}$ \\ Department of Materials Science and Engineering \& National Research Laboratory for Nanophotonic \\ Semiconductor, Gwangju Institute of Science and Technology, Gwangju 500-712, Korea
}

Kyoung-Kook Kim

Research Center for Photovoltaics, National Institute of Advanced Industrial Science and Technology 1-1-1 Umezono, Tsukuba, Ibaraki 305-8586, Japan

D. C. Look

Semiconductor Research Center, Wright State University, Dayton, Ohio 45435

Y. S. Park

School of Physics, Seoul National University, Seoul, Korea

(Received 15 September 2004; accepted 14 February 2005; published online 8 April 2005)

\begin{abstract}
Phosphorus-doped $p$-type $\mathrm{ZnO}$ thin films were grown on sapphire by radio-frequency magnetron sputtering. The photoluminescence (PL) spectra revealed an acceptor bound exciton peak at 3.355 $\mathrm{eV}$ and a conduction band to the acceptor transition caused by a phosphorus related level at 3.310 $\mathrm{eV}$. A study of the dependence of the excitation laser power density and temperature on the characteristics of the PL spectra suggests that the emission lines at 3.310 and $3.241 \mathrm{eV}$ can be attributed to a conduction band to the phosphorus-related acceptor transition and a donor to the acceptor pair transition, respectively. The acceptor energy level of the phosphorus dopant was estimated to be located $127 \mathrm{meV}$ above the valence band. (C) 2005 American Institute of Physics. [DOI: $10.1063 / 1.1895480]$
\end{abstract}

In recent years, wide band gap optoelectronic research based on $\mathrm{ZnO}$ has been stimulated by the need for blue and ultraviolet solid-state light emitters and detectors. ZnO-based optical devices are expected to be highly efficient and practical due to the large exciton binding energy $(\sim 60 \mathrm{meV})$, the high radiation resistance, the availability of large area $\mathrm{ZnO}$ substrates, the amenability to wet chemical etching, and relatively low materials costs. ${ }^{1,2}$ However, $\mathrm{ZnO}$ has several drawbacks, including lack of reproducible and high quality $p$-type material. Several groups have recently reported on the growth of $p$-type $\mathrm{ZnO}$ using a pure metal $\mathrm{Zn}$ target in a $\mathrm{N}_{2} \mathrm{O}$ plasma, using a $\mathrm{ZnO}$ target mixed with $\mathrm{P}_{2} \mathrm{O}_{5},{ }^{3,4}$ Several research groups have also proposed a co-doping method where $\mathrm{N}$ and group III elements such as $\mathrm{Ga}$ and $\mathrm{Al}$ are used as dopants to produce $p$-type $\mathrm{ZnO} .^{5-8} \mathrm{In}$ addition to co-doping methods, it has been reported that $p$-type $\mathrm{ZnO}$ thin films can be grown by doping $\mathrm{ZnO}$ thin films with As contained in the GaAs substrate or with $\mathrm{N}$, a popular $p$-type dopant that has been used by many research groups. ${ }^{9-13}$ We recently reported on a reproducible and effective route to the production of $p$-type $\mathrm{ZnO}$ thin films with a high hole concentration by sputtering a $\mathrm{ZnO}$ target mixed with $\mathrm{P}_{2} \mathrm{O}_{5}$ at high temperatures followed by a rapid thermal annealing process. ${ }^{14}$ Asgrown $\mathrm{ZnO}$ films doped with phosphorus have been shown to have an electron concentration of $10^{16}-10^{17} \mathrm{~cm}^{-3}$ and these films can be converted to $p$-type $\mathrm{ZnO}$ by a rapid thermal annealing process at a temperature above $800{ }^{\circ} \mathrm{C}$ under a $\mathrm{N}_{2}$ ambient. ${ }^{14}$ Hall measurements of a phosphorus doped $p$-type $\mathrm{ZnO}$ ( $p$-type $\mathrm{ZnO}: \mathrm{P}$ ) film showed a high hole concen-

\footnotetext{
${ }^{\text {a) }}$ Author to whom correspondence should be addressed; electronic mail: sjpark@gist.ac.kr
}

tration of $1.0 \times 10^{17}-1.7 \times 10^{19} \mathrm{~cm}^{-3}, \quad$ a mobility of $0.53-3.51 \mathrm{~cm}^{2} / \mathrm{V} \mathrm{s}$, and a low resistivity of $0.59-4.4 \Omega \mathrm{cm} .{ }^{14}$ In this study, we further investigated the effects of phosphorus doping on the optical properties of $\mathrm{ZnO}$ thin films by means of photoluminescence (PL) measurements. The emission lines at 3.355, 3.310, and $3.241 \mathrm{eV}$ were found to be phosphorus-related peaks and the acceptor energy level of phosphorus dopant was estimated to be at $127 \mathrm{meV}$ above the valence band.

The undoped $\mathrm{ZnO}$ thin film was grown on a $c$-plane sapphire $\left(a-\mathrm{Al}_{2} \mathrm{O}_{3}\right)$ at $900{ }^{\circ} \mathrm{C}$ by the radio-frequency magnetron sputtering of an undoped $\mathrm{ZnO}$ target. $p$-Type $\mathrm{ZnO}: \mathrm{P}$ thin films were also grown on a $c$-plane sapphire $\left(a-\mathrm{Al}_{2} \mathrm{O}_{3}\right)$ at $700{ }^{\circ} \mathrm{C}$ by doping phosphorus into $\mathrm{ZnO}$ thin films using a $\mathrm{ZnO}$ target mixed with $1 \mathrm{wt} \% \mathrm{P}_{2} \mathrm{O}_{5}$. Typical film thicknesses of undoped and phosphorus $\mathrm{ZnO}$ were 1 and $0.4 \mu \mathrm{m}$, respectively. Hall measurements were carried out in the Van der Pauw configuration using a direct current of $0.2 \mu \mathrm{A}$ and a magnetic field of $320 \mathrm{G}$ (BIO-RAD HL5500PC). These measurements showed that the undoped $\mathrm{ZnO}$ has an electron concentration of $1.73 \times 10^{12} \mathrm{~cm}^{-3}$, an electron mobility of $21.2 \mathrm{~cm}^{2} / \mathrm{V} \mathrm{s}$, and a resistivity of $1.71 \times 10^{5} \Omega \mathrm{cm}$ and the $p$-type $\mathrm{ZnO}: \mathrm{P}$ has a hole concentration of $5 \times 10^{18} \mathrm{~cm}^{-3}$, a hole mobility of $2 \mathrm{~cm}^{2} / \mathrm{V} \mathrm{s}$, and a resistivity of $2 \Omega \mathrm{cm}$. PL spectra of $p$-type $\mathrm{ZnO}: \mathrm{P}$ thin films were obtained using a He-Cd laser $(\lambda=325 \mathrm{~nm})$ over a range of temperatures $(10-80 \quad \mathrm{~K})$ and excitation laser power densities $\left(6-30 \mathrm{~mW} / \mathrm{cm}^{2}\right)$ in order to study the phosphorus related energy levels in the band gap.

The PL spectrum of an undoped $\mathrm{ZnO}$ showed two strong peaks at $3.363 \mathrm{eV}$ with a full width at half maximum (FWHM) of $7 \mathrm{meV}$ and at $3.352 \mathrm{eV}$ with a FWHM of $8 \mathrm{meV}$, 


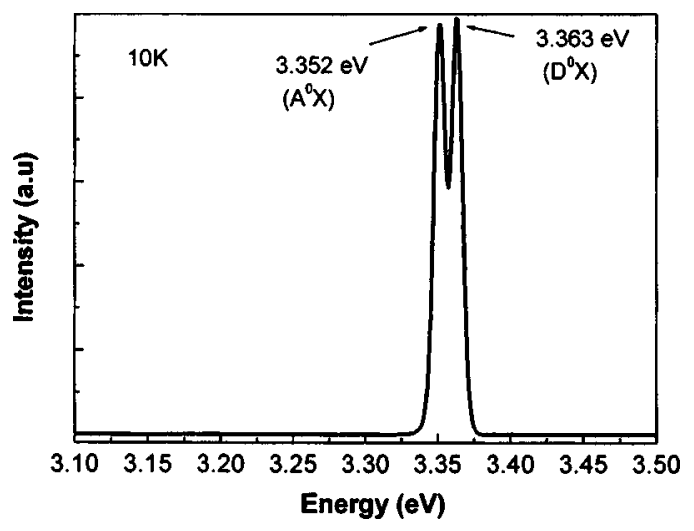

FIG. 1. PL spectra of undoped $\mathrm{ZnO}$ films measured at $10 \mathrm{~K}$.

as shown in Fig. $1{ }^{15}$ The peak at $3.363 \mathrm{eV}$ can be assigned to a donor bound exciton $\left(\mathrm{D}^{0} \mathrm{X}\right)$ having a donor binding energy of $56 \mathrm{meV}{ }^{16}$ The peak at $3.352 \mathrm{eV}$ has been previously identified as an acceptor bound exciton $\left(\mathrm{A}^{0} \mathrm{X}\right)$ having an acceptor binding energy of $94 \mathrm{meV} .{ }^{17}$ Figure 2(a) depicts the PL spectrum of $p$-type $\mathrm{ZnO}: \mathrm{P}$, in which the PL peaks appear at

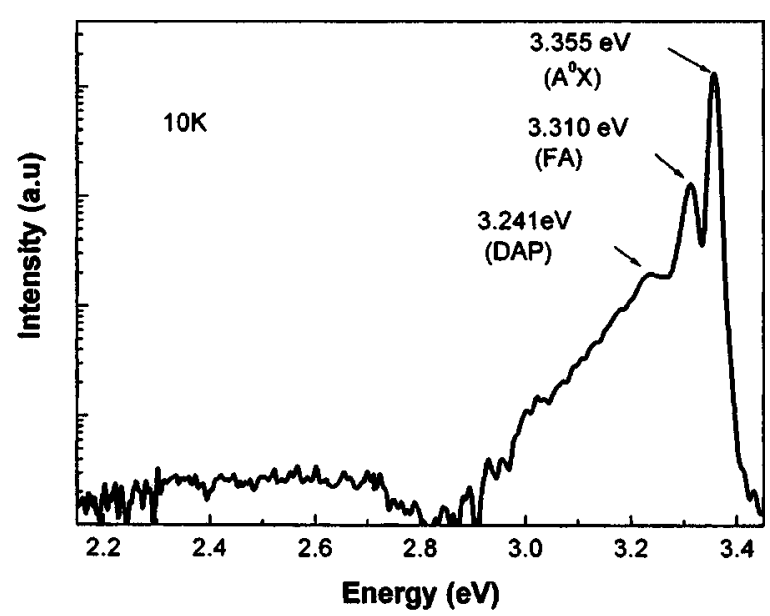

(a)

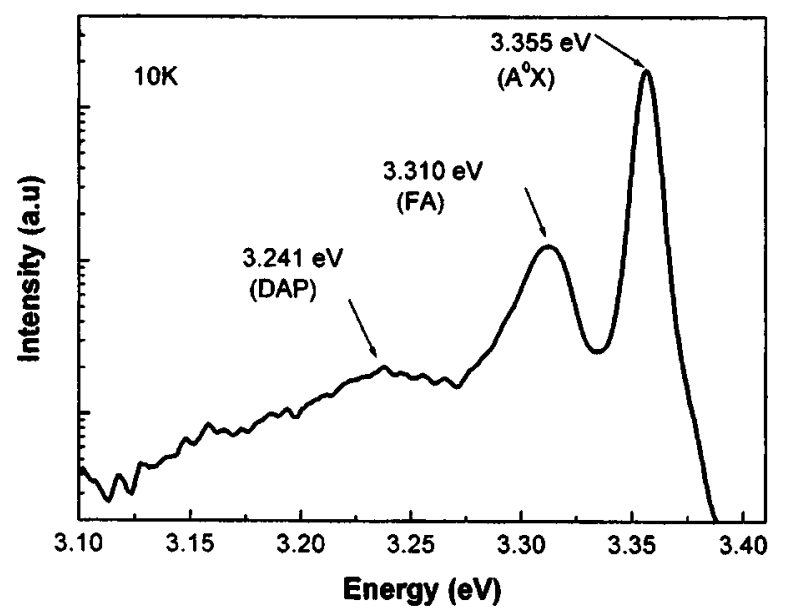

(b)

FIG. 2. PL spectra of $p$-type ZnO:P films measured at $10 \mathrm{~K}$. (a) Wide scale of the PL spectra, from a deep level to band edge emissions; (b) narrow scale of the PL spectra showing near band edge emissions.

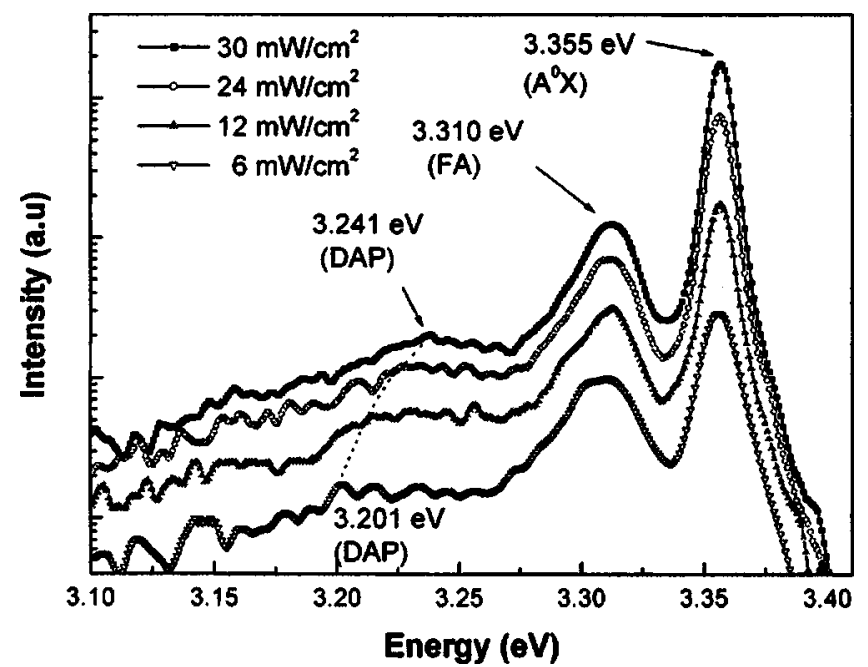

FIG. 3. The dependence of excitation power density on the PL spectra of a $\mathrm{ZnO}: \mathrm{P}$ film at a laser power density of $6-30 \mathrm{~mW} / \mathrm{cm}^{2}$ at $10 \mathrm{~K}$.

$3.355,3.310$, and $3.241 \mathrm{eV}$ without any strong deep level emission. Deep level emission is related to a variety of defects such as donor defect $\mathrm{Zn}$ interstitial $\left(\mathrm{Zn}_{I}\right)$, O vacancy $\left(\mathrm{V}_{\mathrm{O}}\right)$, acceptor defect $\mathrm{Zn}$ vacancy $\left(\mathrm{V}_{\mathrm{Zn}}\right),{ }^{18}$ and antisite defect $\mathrm{O}$ substitutional $\mathrm{Zn}\left(\mathrm{O}_{\mathrm{Zn}}\right)^{19}$ due to the poor stoichiometry of $\mathrm{ZnO}$. The very weak deep level emission indicates that the $p$-type $\mathrm{ZnO}: \mathrm{P}$ has very few native donor and acceptor defects and the observed acceptor related PL emissions and hole concentration are not due to the native defects but are due to the phosphorus dopant in ZnO. In Fig. 2(b), the PL spectrum of phosphorus-doped $\mathrm{ZnO}$ film clearly shows a peak at 3.355 $\mathrm{eV}$ which can be attributed to $\mathrm{A}^{0} \mathrm{X}$ and two other peaks at 3.310 and at $3.241 \mathrm{eV}$ which are related to acceptors. Peaks at 3.310 and $3.241 \mathrm{eV}$ were not observed on the PL spectrum of undoped $\mathrm{ZnO}$, as shown in Fig.1. These new peaks shown in Fig. 2(b) were observed only on the intentionally phosphorus-doped $p$-type $\mathrm{ZnO}$ and suggest that they are closely related to phosphorus-related acceptor transitions. We further investigated the origin of PL emissions at 3.310 and $3.241 \mathrm{eV}$ by studying the laser power density and temperature dependence of PL since the origin of the emission for a phosphorus dopant have not been reported yet.

For a donor to acceptor pair (DAP) transition, the energy of the photon resulting from radiative recombination is given by

$$
h \nu_{\mathrm{DA}}=E_{g}-E_{D}-E_{A}+\frac{e^{2}}{4 \pi \varepsilon R_{\mathrm{DA}}}
$$

where $E_{g}, E_{D}$, and $E_{A}$ are the band gap, donor and acceptor binding energies, respectively, $\varepsilon$ the dielectric constant, $R_{\mathrm{DA}}$ the distance between the involved donor and acceptor. ${ }^{20}$ When the excitation intensity is increased, the number of occupied donor and acceptor centers increases and their average distance $R_{\mathrm{DA}}$ decreases. Consequently, it would be expected that the emission line of the pair band would shift to higher energy with increasing excitation intensity due to the Coulomb term. Figure 3 shows the laser power density dependent PL spectra of $p$-type $\mathrm{ZnO}$ excited by laser power densities in the range from 6 to $30 \mathrm{~mW} / \mathrm{cm}^{2}$ at $10 \mathrm{~K}$. As shown in Fig. 3, the peak position at $3.310 \mathrm{eV}$ is independent of the laser power density at $10 \mathrm{~K}$, whereas the peak at 3.241 $\mathrm{eV}$ shifts to the lower energy side with decreasing laser 


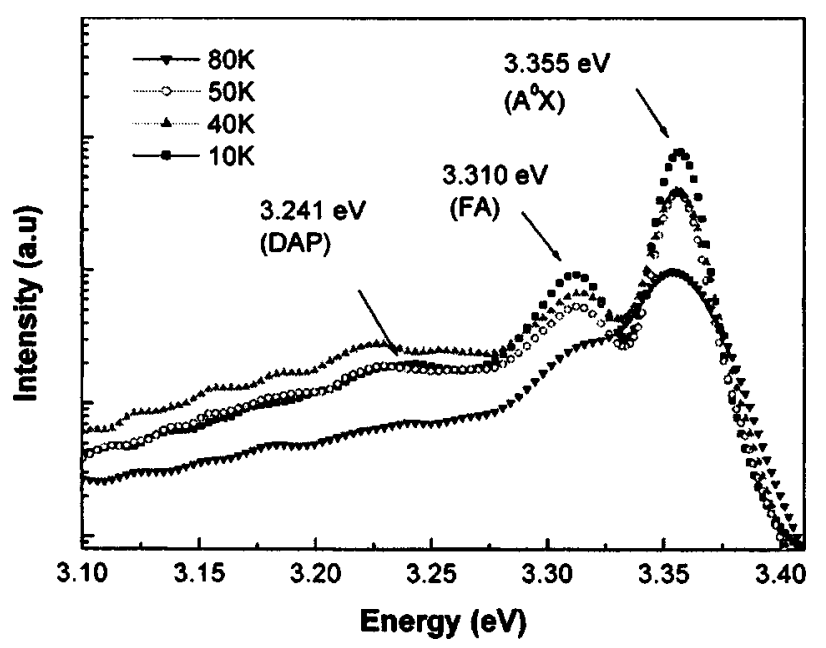

FIG. 4. Temperature dependent PL spectra for a $\mathrm{ZnO}: \mathrm{P}$ film in the temperature range of $10-80 \mathrm{~K}$.

power density. This observation strongly suggests that the origin of the emission peak at $3.241 \mathrm{eV}$ is from the DAP transition and the emission peak at $3.310 \mathrm{eV}$ can be attributed to the conduction band to acceptor transition [or free electrons to the acceptor (FA) transition].

The temperature dependent PL spectra of a $p$-type $\mathrm{ZnO}: \mathrm{P}$ film was also measured and these data are shown in Fig. 4. The integrated intensity of the peak emission at 3.310 $\mathrm{eV}$ decreases gradually with increasing temperature, as shown in Fig. 4, exhibiting the thermal characteristic of the FA transition. ${ }^{21}$ However, the peak intensity of the emission at $3.241 \mathrm{eV}$ increased with increasing temperature from 10 to $40 \mathrm{~K}$, as shown in Fig. 4. The increase in peak intensity at $3.241 \mathrm{eV}$ can be explained by the thermal release of electrons from the shallow donor level. ${ }^{22}$ This result and the shift of the peak at $3.241 \mathrm{eV}$ to the high energy side with increasing excitation power as shown in Fig. 3 indicates that the emission at $3.241 \mathrm{eV}$ is due to the DAP transition. Previous studies of PL have shown that the FA and DAP emissions appear at 3.322 and $3.204 \mathrm{eV}$ for $p$-type $\mathrm{ZnO}: \mathrm{As},{ }^{23}$ respectively, and DAP emission is observed at $3.238 \mathrm{eV}$ for $p$-type $\mathrm{ZnO}: \mathrm{N}^{10}$ The PL results in this study show that the DAP emission at $3.241 \mathrm{eV}$ from $p$-type $\mathrm{ZnO}: \mathrm{P}$ is very similar to results for $\mathrm{N}$-doped $p$-type $\mathrm{ZnO}$ and the FA emission peak from $p$-type $\mathrm{ZnO}: \mathrm{P}$ is significantly different from that of As doped $p$ - $\mathrm{ZnO}$.

The acceptor energy of the phosphorus dopant was estimated from the FA transition at $3.310 \mathrm{eV}$ PL spectra of p-type $\mathrm{ZnO}: \mathrm{P}$. The FA energy is given by

$$
E_{F A}=E_{g}-E_{A}+\frac{k_{B} T}{2},
$$

where $E_{g}$ and $E_{A}$ are the band gap and acceptor energies, respectively. The optical binding energy of phosphorus acceptors can be estimated from the equation $E_{F A}(3.310 \mathrm{eV})$ $=E_{g}(3.437 \mathrm{eV})-E_{A}+\left(k_{B} T / 2\right)$. Since the thermal energy term can be neglected at $10 \mathrm{~K}$, we obtain an $E_{A}$ value of $127 \mathrm{meV}$ at a hole concentration of $5 \times 10^{18} \mathrm{~cm}^{-3}$. The analysis of PL spectra showed that the acceptor energy levels of As doped and $\mathrm{N}$ doped $p$-type $\mathrm{ZnO}$ are in the range of $115-164 \mathrm{meV}$ at a $4 \times 10^{17} \mathrm{~cm}^{-3}$ hole concentration, ${ }^{23}$ and $170-200 \mathrm{meV}$ at a $9 \times 10^{16} \mathrm{~cm}^{-3}$ hole concentration, ${ }^{10}$ respectively. The shallow acceptor energy level of $127 \mathrm{meV}$ suggests that the use of phosphorus as an acceptor in $\mathrm{ZnO}$ would be very desirable, in terms of obtaining a high hole concentration in $p$-type $\mathrm{ZnO}$.

In summary, a thermal activation of phosphorus-doped $\mathrm{ZnO}$ thin films showed a good $p$-type conductivity with a hole carrier concentration of $5 \times 10^{18} \mathrm{~cm}^{-3}$ at room temperature. The PL spectra revealed an acceptor bound exciton peak at $3.355 \mathrm{eV}$ and phosphorus-related peaks at 3.310 and $3.241 \mathrm{eV}$. A temperature dependence study and the dependence of laser power on the PL spectra at $10 \mathrm{~K}$ revealed that the emission line at $3.241 \mathrm{eV}$ is due to a DAP transition and the emission line at $3.310 \mathrm{eV}$ can be attributed to the FA transition. The acceptor energy level was estimated to be located at $127 \mathrm{meV}$ above the valence band, resulting in a high hole concentration in the $p$-type $\mathrm{ZnO}: \mathrm{P}$ compared to As or $\mathrm{N}$ doped $p$-type $\mathrm{ZnO}$.

This work was partially supported by the National Research Laboratory Program for Nanophotonic Semiconductors in Korea and the U.S. Air Force Office of Scientific Research .

${ }^{1}$ Y. Chen, D. Bagnall, and T. Yao, Mater. Sci. Eng., B 75, 190 (2000).

${ }^{2}$ D. C. Look, Mater. Sci. Eng., B 80, 383 (2001).

${ }^{3}$ X.-L. Guo, H. Tabata, and T. Kawai, J. Cryst. Growth 223, 135 (2001).

${ }^{4}$ Y. W. Heo, S. J. Park, K. Ip, S. J. Pearton, and D. P. Norton, Appl. Phys. Lett. 83, 1128 (2003).

${ }^{5}$ T. Yamamoto and H. Yoshida, Jpn. J. Appl. Phys., Part 2 38, L166 (1999).

${ }^{6}$ M. Joseph, H. Tabata, and H. Saeki, K. Ueda, and T. Kawai, Physica B 302-303, 140 (2001).

${ }^{7}$ K. Nakahara, H. Takasu, P. Fons, A. Yamada, K. Iwata, K. Matsubara, R. Hunger, and S. Niki, Appl. Phys. Lett. 79, 4139 (2001).

${ }^{8}$ A.Tsukazaki, H. Saito, K. Tamura, M. Ohtani, H. Koinuma, M. Sumiya, S. Fuke, T. Fukumura, and M. Kawasaki, Appl. Phys. Lett. 81, 235 (2002).

${ }^{9}$ A. B. M. A. Ashrafi, I. Suemune, H. Kumano, and S. Tanaka, Jpn. J. Appl. Phys., Part 2 41, L1281 (2002).

${ }^{10}$ D. C. Look, D. C. Reynolds, C. W. Litton, R. L. Jones, D. B. Eason, and G. Cantwell, Appl. Phys. Lett. 81, 1830 (2002).

${ }^{11}$ S. J. Pearton, C. R. Abernathy, M. E. Overberg, G. T. Thaler, D. P. Norton, N. Theodoropoulou, A. F. Hebard, Y. D. Park, F. Ren, J. Kim, and L. A. Boatner, J. Appl. Phys. 93, 1 (2003).

${ }^{12}$ Y. R. Ryu, S. Zhu, D. C. Look, J. M. Wrobel, H. M. Jeong, and H. W. White, J. Cryst. Growth 216, 330 (2000).

${ }^{13}$ K. Iwata, P. Fons, A. Yamada, K. Matsubara, and S. Niki, J. Cryst. Growth 209, 526 (2000)

${ }^{14}$ K.-K. Kim, H.-S. Kim, D.-K. Hwang, J.-H. Lim, and S.-J. Park, Appl. Phys. Lett. 83, 63 (2003).

${ }^{15}$ H. J. Ko, Y. F. Chen, Z. Zhu, T. Yao, I. Kobayashi, and H. Uchiki, Appl. Phys. Lett. 76, 1905 (2000).

${ }^{16}$ D. C. Reynolds, D. C. Look, B. Jogai, C. W. Litton, T. C. Collins, W. Harsch, and G. Cantwell, Phys. Rev. B 57, 12151 (1998).

${ }^{17}$ J. Gutowski, N. Presser, and I. Broser, Phys. Rev. B 38, 9746 (1988).

${ }^{18}$ K. Vanheusden, W. L. Warren, C. H. Seager, D. R. Tallant, J. A. Voigt, and B. E. Gnade, J. Appl. Phys. 79, 7983 (1996).

${ }^{19}$ B. Lin, Z. Fu, and Y. Jia, Appl. Phys. Lett. 79, 943 (2001).

${ }^{20}$ J. K. Sheu and Y. K. Su, J. Appl. Phys. 84, 4590 (1998).

${ }^{21}$ J. M. Myoung, K. H. Shim, C. Kim, K. Kim, S. Kim, and S. G. Bishop, Appl. Phys. Lett. 69, 2722 (1996).

${ }^{22}$ M. A. Reshchikov, G.-G. Yi, and B. W. Wessels, Phys. Rev. B 59, 13176 (1999).

${ }^{23}$ Y. R. Ryu, T. S. Lee, and H. W. White, Appl. Phys. Lett. 83, 87 (2003). 